\title{
Effect of panel shape on hydrodynamic performances of vertical v-shaped double-slotted cambered otter-board
}

\author{
Lei $W A N G^{1}$, Xun ZHANG ${ }^{1}$, Lu Min WANG ${ }^{1,}$, Hong Liang HUANG ${ }^{1}$, Yu ZHANG ${ }^{1}$, Yong Li LIU ${ }^{1}$, Wei Dong FENG ${ }^{2}$ and \\ Rong Jun ZHANG
}

${ }^{1}$ Key Laboratory of Oceanic and Polar Fisheries, Ministry of Agriculture; East China Sea Fisheries Research Institute, Chinese Academy of Fishery Sciences, Shanghai 200090, China

${ }^{2}$ China National Fisheries Corporation, Beijing 100032, China

\begin{abstract}
The effect of panel shape on hydrodynamic performances of a vertical v-shaped doubleslotted cambered otter-board was investigated using engineering models in a wind tunnel. Three different shape panels (rhomboid, left trapezoid and isosceles trapezoid) were evaluated at a wind speed of $28 \mathrm{~m} / \mathrm{s}$. Parameters measured included: drag coefficient $C_{x}$, lift coefficient $C_{y}$, pitch moment coefficient $\mathrm{C}_{\mathrm{m}}$, center of pressure coefficient $\mathrm{C}_{\mathrm{p}}$, over a range of angle of attack $\left(0^{\circ}\right.$ to $70^{\circ}$ ). These coefficients were used in analyzing the differences in the performance among the three otter-board models. Results showed that the maximum lift coefficient $\mathrm{C}_{\mathrm{y}}$ of the otter-board model with the isosceles trapezoid shape panels was highest $\left(2.103\right.$ at $\left.\alpha=45^{\circ}\right)$. The maximum $\mathrm{C}_{\mathrm{y}} / \mathrm{C}_{\mathrm{x}}$ of the otter-board with the rhomboid shape panels was highest $\left(3.976\right.$ at $\left.\alpha=15^{\circ}\right)$. A comparative analysis of $\mathrm{C}_{\mathrm{m}}$ and $\mathrm{C}_{\mathrm{p}}$ showed that the stability of otter-board model with the isosceles trapezoid shape panels is better in pitch, and the stability of otter-board model with the left trapezoid shape panels is better in roll. The findings of this study can offer useful reference data for the structural optimization of otter-boards for trawling.
\end{abstract}

\section{Introduction}

Otter boards are an important part of fishing gear for spreading the trawl mouth. The merits of the hydrodynamic performance of otter-boards can be measured on the basis of the lift coefficient and the drag coefficient of the trawl door [1]. Optimizing the structure of otter-boards may improve the hydrodynamic performance of the otter-board and reduce the energy consumption of fishing vessels [2-3]. Extensive studies on the hydrodynamic performance of otter-boards have been conducted in the United States, Japan, Norway, and other countries [4-8]. In China, researchers have studied the relevant hydrodynamic performance of otter-boards since the early 1980s, including the hydrodynamic performance and optimization of different otter-boards with various structure types [9-13]. The development of offshore trawler fleets has increased globally in recent decades, raising the demand for improved otter-board designs. Accordingly, improvements in the hydrodynamic performance of otter-boards has become a major research interest. Some studies have shown that the slit in otter-boards can reduce the resistance and improve the stability of otter-boards [14-19]. The following study investigates the influence of three kind of shapes of the panel within the otter-board, including the rhomboid, left trapezoid and isosceles trapezoid. We describe an experiment using model otter-boards ( $\mathrm{n}=3$ designs) in a wind tunnel in which we measured various hydrodynamic coefficients for a range of angles of attack. The results are relevant as a reference for the study of the structural parameters of otter-boards.

\section{Material and Methods}

\subsection{Design and manufacture of otter-board model}

The otter-boards evaluated in this study were vertical vshaped double-slit curved structures comprising two deflectors and a main-panel (figure 1). This design was based on the structure of the otter-board used in bottom trawl currently. Only the shape of the panels was modified with three kind of shapes.

\footnotetext{
* Corresponding author: zhangxun007@,hotmail.com
} 

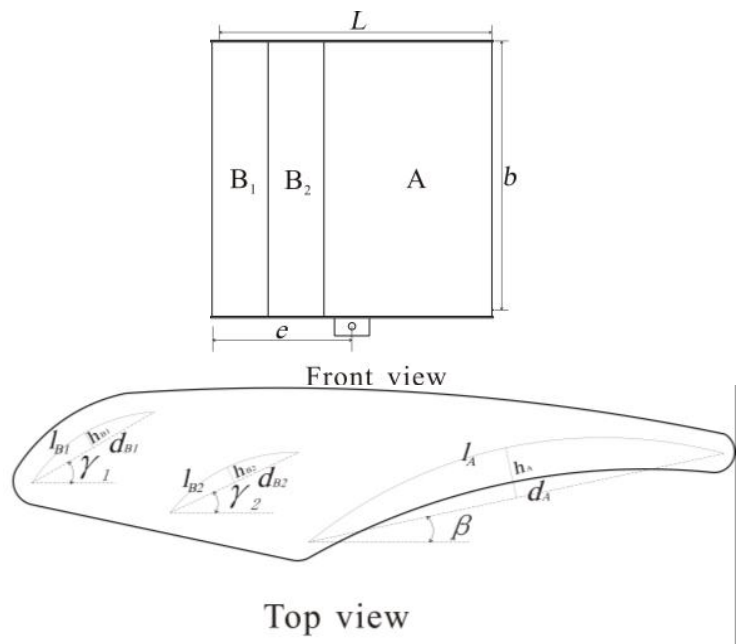

Fig. 1. Structure and parameters of otter-board

Note: L: chord; b: span; e: distance between fulcrum and the front end of model; $\mathrm{B}_{1}, \mathrm{~B}_{2}$ : deflector; A: main-panel; $\gamma_{1}, \gamma_{2}$ : deflector angle of mid-plate; $\beta$ : angle of main-panel of midplate; $\gamma^{\prime} 1, \gamma^{\prime} 2$ : deflector angle of up-plate; $\beta^{\prime}$ : angle of mainpanel of up-plate; lB1, lB2: arc length of deflector of mid-plate; $1_{\mathrm{A}}$ : arc length of main-panel of mid-plate; $1^{\prime}{ }_{\mathrm{B} 1}, 1^{\prime}{ }_{\mathrm{B} 2}$ : arc length of deflector of up-plate; $1^{\prime}{ }_{A}$ : arc length of main-panel of up-plate.

Each of models had an aspect ratio of 1.0, surface area of $0.25 \mathrm{~m} 2$, and were identical in many structural parameters and dimensions (table 1). The curvature of the deflector and main panels was $12 \%$ and was consistent in all models. The only parameter that varied between the models was the arc length of panels (lB1, 1B2, 1A; 1 B1, 1 B2, 1 A), and the parameters of panels of up-plate was same to down-plate. The models are made of steel with painted surfaces (figure 2).

Table 1. Descriptive characteristics of the four model otter boards evaluated in this study.

\begin{tabular}{|c|c|c|c|}
\hline No. & 1 & 2 & 3 \\
\hline$L / \mathbf{m}$ & 0.5 & 0.5 & 0.5 \\
\hline$b / \mathbf{m}$ & 0.5 & 0.5 & 0.5 \\
\hline$\lambda$ & 1 & 1 & 1 \\
\hline$S / \mathbf{m}^{2}$ & 0.25 & 0.25 & 0.25 \\
\hline$e / \mathbf{m}$ & 0.25 & 0.25 & 0.25 \\
\hline$\gamma_{1}=\gamma^{\prime}{ }_{1}$ & $30^{\circ}$ & $30^{\circ}$ & $30^{\circ}$ \\
\hline$\gamma_{2}=\gamma_{2}^{\prime}$ & $25^{\circ}$ & $25^{\circ}$ & $25^{\circ}$ \\
\hline $\boldsymbol{\beta}=\boldsymbol{\beta}^{\prime}$ & $6^{\circ}$ & $6^{\circ}$ & $6^{\circ}$ \\
\hline$l_{B 1}=l_{B 2}$ & 0.127 & 0.149 & 0.171 \\
\hline$l_{A}$ & 0.313 & 0.336 & 0.357 \\
\hline$l^{\prime}{ }_{B 1}=l^{\prime}{ }_{B 2}$ & 0.127 & 0.105 & 0.083 \\
\hline$l_{A}^{\prime}$ & 0.313 & 0.292 & 0.27 \\
\hline$S_{B 1}=S_{B 2}$ & 0.032 & 0.032 & 0.032 \\
\hline$S_{A}$ & 0.078 & 0.078 & 0.078 \\
\hline
\end{tabular}

Note: $L$ : chord; b: span; $\lambda$ : aspect ratio $(\mathrm{b} / \mathrm{L}) ; \mathrm{S}$ : surface area $(L \cdot b)$; e: distance between fulcrum and the front end of model; $\gamma_{1}, \gamma_{2}$ : deflector angle of mid- plate; $\beta$ : main-panel angle of mid-plate; $1_{\mathrm{B} 1}$, l $\mathrm{B}_{2}$ : arc length of deflector of mid- plate; $1_{\mathrm{A}}$ : arc length of main-panel of mid- plate; $\gamma^{\prime}{ }_{1}, \gamma_{2}^{\prime}$ : deflector angle of up- plate; $\beta^{\prime}$ : main-panel angle of up- plate; $1^{\prime}{ }_{1}$, $l^{\prime}{ }_{\mathrm{B} 2}$ : arc length of deflector of up- plate; $1^{\prime}{ }_{\mathrm{A}}$ : arc length of main-panel of upplate.
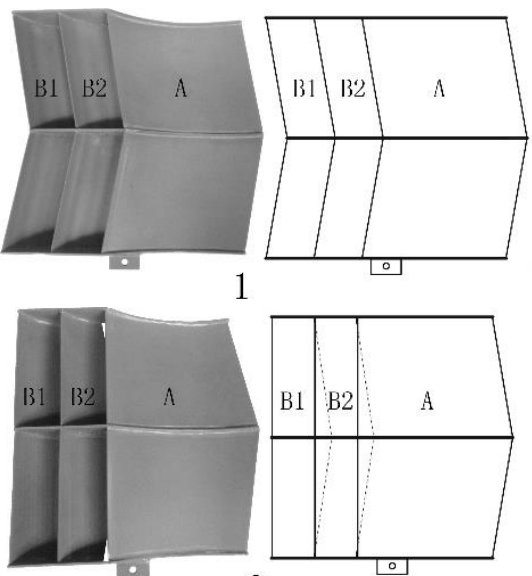

2

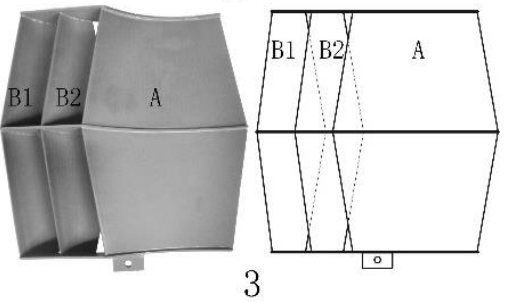

Fig. 2. Three otter-board models with different panel shapes evaluated in this study.

Note: 1: rhomboid; 2: left trapezoid; 3: isosceles trapezoid; A: main-panel; $\mathrm{B}_{1}, \mathrm{~B}_{2}$ : deflector.

\subsection{Test facility}

The wind tunnel used for this experiment was the NH-2 wind tunnel located at Nanjing University of Aeronautics and Astronautics, China. The tunnel is a closed reflux wind tunnel with a double-string test section. The experiment was conducted in a small test section. Dimensions of the test section were $6 \mathrm{~m}$ (length) $\times 3 \mathrm{~m}$ (width) $\times 2.5 \mathrm{~m}$ (height). The cross-sectional area was $7.18 \mathrm{~m}^{2}$. The minimum and maximum wind speeds of the tunnel were $5 \mathrm{~m} / \mathrm{s}$ and $90 \mathrm{~m} / \mathrm{s}$, respectively. Figure 3 illustrates the experimental setup inside the wind tunnel. The otter-board models were attached to a dynamometer compromising a six-component mechanical tower-balance to measure forces in all directions. The data acquisition and processing system used is composed of a pre -amplifier and a four networked computer system.

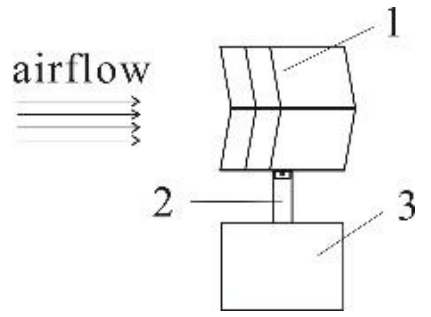

Fig. 3. Installation instruction of otter-board model in wind tunnel.

Note: 1.otter-board model 2.model connection 3.six-component force balance

\subsection{Test method}




\subsubsection{Parameter definition of test model}

Test model need to be installed on the wind tunnel in six-component balance mechanical base according to the order, angle of attack of model rotates by the $0^{\circ}-70^{\circ}$ when the wind speed reaches $28 \mathrm{~m} / \mathrm{s}$ (room temperature $20{ }^{\circ} \mathrm{C}$ ), wherein the angle of attack in the range $0^{\circ}-50^{\circ}$, $2.5^{\circ}$ intervals to record a measurement data point, after the attack angle $50^{\circ}$, each measurement interval of $5^{\circ}$ to record data points, there are 25 sets of data totally, including the drag coefficient $C_{x}$, the lift coefficient $C_{y}$, the pitch moment coefficient $C_{\mathrm{m}}$ and the center of pressure coefficient $C_{\mathrm{p}}$.

The relevant parameters of models in the wind tunnel test section are defined as shown in figure 4. In figure 4, $\mathrm{O}$ is torque reference point, which is the punch of the model at the bottom. During the test, the resistance of the model is provided by the force of balance along the Xaxis direction, the lift is provided by the force of balance along the Z-axis direction, and the pitch moment is provided by the $M_{\mathrm{y}}$ of balance along the $\mathrm{Z}$-axis direction.

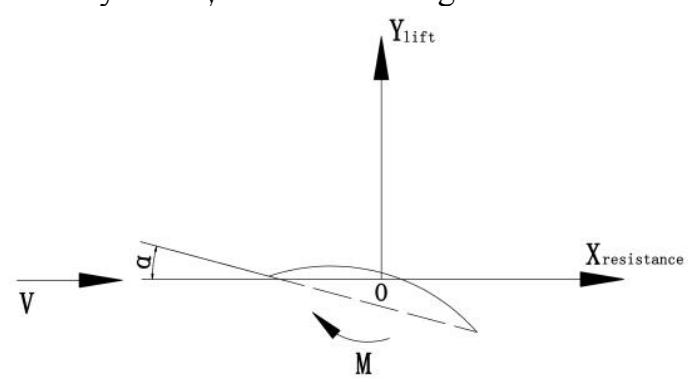

Fig. 4. Parameter definition diagram of test model in wind tunnel.

For this test, Wind speed $V=28 \mathrm{~m} / \mathrm{s}$, when the Reynolds number $R_{e}=V L / v=0.93 \times 10^{6}$ (coefficient of viscosity $\left.v=15 \times 10^{6} \mathrm{~m}^{2} \cdot \mathrm{s}^{-1}\right)[14]$.

\subsubsection{Parameter definition of test measurement}

Three components: lift $Y$, drag $X$, pitching moment $M$ (around the fulcrum), while the distance from the center of pressure to the front-end otter-board $d=e-(M / N)$ [16], ( $N$ is the normal force).

Lift coefficient

$$
C_{y}=\frac{Y}{\rho V^{2} S / 2}
$$

[3]; drag

coefficient

$$
C_{x}=\frac{X}{\rho V^{2} S / 2} \quad ; \quad \text { pitch moment }
$$

coefficient $C_{m}=\frac{M}{\rho V^{2} S L / 2} \quad ; \quad$ center of pressure coefficient $_{C_{p}}=\frac{d}{L}$.

Air density $\rho=1.225 \mathrm{~kg} / \mathrm{m}^{3}$ in above formula; $S$ is otter-board area $\left(\mathrm{m}^{2}\right) ; L$ is the otter-board chord length (m).

All the experimental data have been carried out the stent disturbance correction which is completed by the method of taking out light pole directly.

\section{Results and Discussion}

\subsection{Drag coefficient and lift coefficient}

Data from the experiment included the drag coefficient $C_{x}$, the lift coefficient $C_{y}$, the pitch moment coefficient $C_{\mathrm{m}}$, and the center of pressure coefficient $C_{p}$. The liftdrag ratio was computed $\left(C_{y} / C_{x}\right)$, which is an important factor for determining the merits of the hydrodynamic performance of otter-boards. An otter-board with excellent hydrodynamic properties can achieve higher lift-drag ratio and improved stability; such performance can be analyzed by comparing the pitching moment coefficient $C_{\mathrm{m}}$ stencil and the center of pressure coefficient $C_{p}$. The test data were divided into groups, yielding $C_{x}-\alpha, C_{y}-\alpha$ and $C_{y} / C_{x}-\alpha$ graphs shown in figure 5 . These graphs are used for analyzing the differences in the hydrodynamic properties of the three otter-board models.
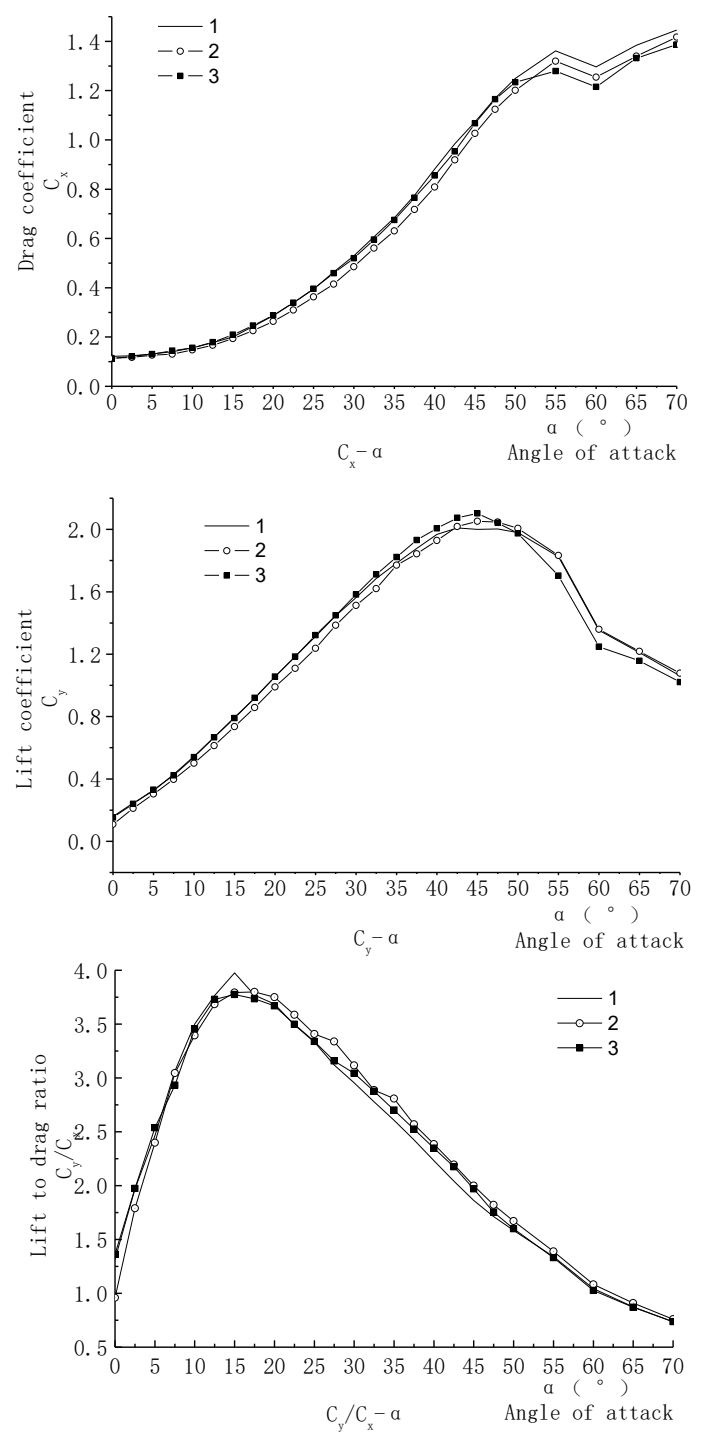

Fig. 5. Hydrodynamic properties of three otter-board models across a range of angle of attack.

In figure 5, $C_{x}-\alpha$ and $C_{y}-\alpha$ graphs show the variation curve of the drag and lift coefficient of the three models while the angle of attack $\alpha$ changes. The relationship between $C_{x}$ and $\alpha$ is proportional almost but a turning point at the angle of attack $60^{\circ}$. The maximum lift coefficients $C_{y}$ of No. 1, No. 2, and No. 3 otter-board models were $2.009\left(\alpha=42.5^{\circ}\right), 2.053\left(\alpha=45^{\circ}\right)$, and 
$2.103\left(\alpha=45^{\circ}\right)$, respectively. It shows that the maximum lift coefficients of No. 3 otter-board is higher.

\subsection{Lift-drag ratio}

In figure 5, the maximum lift-drag ratios of No.1 model with the rhomboidal panels is the highest, there is 3.976 $\left(\alpha=15^{\circ}\right)$. The maximum lift-drag ratios of No. 2 and No. 3 models are $3.799\left(\alpha=17.5^{\circ}\right)$ and $3.774\left(\alpha=15^{\circ}\right)$, respectively.

\subsection{Stability of otter-board}

Pitching moment can be divided into upper and lower pitching moments, which are usually distinguished by positive and negative values, Positive means the otterboard tilts backward, and negative means tilts forward. Its absolute value represents the level of pitching moment; and the pitching moment coefficient tending to 0 represents the more excellent stability of otter-board. In practice, comparing the absolute value $C_{m}$ corresponding to the operation angle of attack of otterboard may determine the stability level of otter-board. For comparison, the angle of attack corresponding to the maximum lift-drag ratio $C_{\mathrm{y}} / C_{\mathrm{x}}$ is selected [20]. The corresponding absolute value of $C_{m}$ is shown in table 2 . The absolute value of $C_{m}$ of No. 3 model is 0.126 , so hence, the stability of No. 3 otter-board model is better in pitch.

Table 2. Parameters of three otter-board models for stability analysis.

\begin{tabular}{|c|c|c|c|}
\hline No. & $\begin{array}{c}\text { Angle } \\
\text { corresponding to } \\
\text { the maximum lift } \\
\text {-drag ratio } \\
\boldsymbol{\alpha}\end{array}$ & $\left|\boldsymbol{C}_{\mathbf{m}}\right|$ & $\begin{array}{c}\text { Variable } \\
\text { coefficient of } \\
\boldsymbol{C}_{\mathbf{p}}\end{array}$ \\
\hline $\mathbf{1}$ & $15^{\circ}$ & 0.174 & $7.10 \%$ \\
\hline $\mathbf{2}$ & $17.5^{\circ}$ & 0.147 & $6.69 \%$ \\
\hline $\mathbf{3}$ & $15^{\circ}$ & 0.126 & $7.55 \%$ \\
\hline
\end{tabular}

The stability in roll of otter-board can be measured according to the center of pressure coefficient $C_{\mathrm{p}}$; and the way of comparison is analyzing the coefficient of variation in $C_{\mathrm{p}}$ within the range of angle approximately $5^{\circ}$ of the angle of attack corresponding to the maximum lift-drag ratio; a smaller coefficient results in the improved stability [21]. The calculated data are shown in table 2. The minimum variation coefficient of $C_{\mathrm{p}}$ is $6.69 \%$; this value also means that the stability of No. 2 otter-board model is better in roll of otter-board.

\section{Conclusion}

Test analysis shows that a vertical V-shaped doubleslotted cambered otter-board with isosceles trapezoid shaped panels has a higher maximum lift coefficient but a lower maximum lift-drag ratio, and the otter-board with rhomboid shaped panels has a higher maximum liftdrag ratio, but a lower maximum lift coefficient. The test results also show that the otter-board with isosceles trapezoid shaped panels is better in lateral stability and should not be tumbled easily. The otter-board with left trapezoidal shaped panels is better in the vertical stability and should not be dumped easily. The results of this study can provide some reference for the structural design of different types of otter-board.

\section{Acknowledgements}

This work is financially supported by the National Key Technology R\&D Program (No. 2013BAD13B04).

\section{References}

1. G. X. Guo, T. Y. Liu, X. H. Huang, F. L. Gu. Theory and Practice of trawl doors Kinetic. Guang. Sci. \& Tech. Pub. (2008)

2. Y. Q. Zhou. Mechanics of fishing gear. Chi. Agr. Pub. (2001)

3. X. Z. Chen, X. C. Huang. Theory and method of gear model test. Sh. Sci. \& Tech. Pub. (2011)

4. A. Sala, J. Prat, J. Antonijuan, A. Lucchetti. Fis. Res. 156, 100(2009)

5. Y. Takahashi, Y. Fujimori, F. X. Hu, X. L. Shen, N. Kimura. Fis. Res. 400, 161(2015)

6. M. K. Broadhurst, D. J. Sterling, R. B. Millar. Fis. Man. \& Eco. 407, 22(2015)

7. K. Fukuda, F. X. Hu, T. Tokai, K. Matuda. Ni. Su. Gak. 97, 66(2000)

8. C. D. Park, K. Matuda, F. X. Hu. Ni. Su. Gak. 920, 62(1996)

9. X. L. Shen, F. X. Hu, T. Kumazawa, D. Shiode, T. Tokai. Fis. Sci. 433, 81(2015)

10. L. Wang, L. M. Wang, C. L. Feng, A. Z. Zhou, W. W. Yu, Y. Zhang, X. Zhang. Aqu. \& Fis. 234, 2(2017)

11. L. Wang, L. M. Wang, J. G. Shi, Y. Zhang, Y. L. Liu, W. W. Yu, X. Zhang. MAT. W. Con. 5004, 128(2017)

12. L. Wang, L. M. Wang, A. Z. Zhou, J. G. Shi, Y. Zhang, G. D. Xu, X. Zhang. MAT. W. Con. 5003, 128(2017)

13. L. Wang, L. M. Wang, C. L. Feng, X. Zhang, A. Z. Zhou, Y. Zhang, Y. L. Liu, G. R. Qi. Mar. Fis. 682, 39(2017)

14. X. Zhang, J. H. Wang, M. Y. Wang, Y. F. Yu, B. S. Xu. Jou. Fis. Sci. Ch. 5, 11(2004)

15. J. H. Wang, M. Y. Wang, X. Zhang, Y. F. Yu, B. S. Xu. Jou. Fis. Sci. Ch. 9, S1(2004)

16. M. Y. Wang, J. H. Wang, X. Zhang, Y. F. Yu, B. S. Xu. Jou. Fis. Ch. 311, 3(2004)

17. C. C. Li, Z. L. Liang, L. Y. Huang, W. F. Zhou, P. Sun, L. Wang. Mar. Sci. 69, 11(2013) 
18. L. Wang, L. M. Wang, C. L. Feng, X. Zhang, J. G. Shi, Y. Zhang, Y. L. Liu, W. W. Yu. Fis. Mod. 55, 6(2015)

19. L. Wang, L. M. Wang, W. W. Yu, C. L. Feng, J. G. Shi, Y. L. Liu, X. Zhang. Con. In. For. En. Sus. De. 530, 75(2016)

20. L. Yang. Fis. Sci. Tec. 38, 2(1996)

21. L. Yang. Fis. Sci. Tec. 42, 5(1996) 